\title{
Personality Development in the Physically Handicapped Child
}

\author{
STUART M. FINCH, M.D.*
}

To ODAY'S pediatrician finds in his practice an increasing number of children with permanent physical handicaps, who in past years would not have survived. And the numbers of these will undoubtedly continue to mount with improving child care practices, currently being stimulated by energetic Federal support.

Attention to such a child's emotional development and treatment of his physical disability are both included in the responsibility of the pediatrician. Sound medical management of the chronic physical problem is pointless if the youngster grows up an emotional cripple because his personality development has been preventably distorted.

The task of rearing a physically handicapped child to healthy adulthood is obviously more complex and burdensome than that of a child who is basically physically sound. Even the most mature parents find it difficult to accept the knowledge of a permanent handicap, whether its presence is discovered at birth or later in childhood, and they usually need professional help in both understanding the handicap and adjusting to it. The pediatrician should know how to provide the parents of a handicapped child with the opportunity to verbalize their concerns about the child's condition, and be able to give them the kind of counselling which will help them attain a realistic attionde toward their child.

\section{Reactions of Parents}

When parents first become aware of a child's handicap, their inevitable reactions

* Chief, Children's Psychiatric Hospital, University Hospital, The University of Michigan, Ann Arbor, Michigan. include feelings of disappointment and resentment, and they tend to wish to be rid of the problem and, in a sense, of the child. For most parents, however, such feelings produce so much guilt that conscious awareness of this cannot be permitted. One or both parents may feel that somehow they are the cause of the problem-because of some behavior problem during pregnancy, or some inherited genetic defect. But whatever the cause, known or unknown, this guilty need to deny may lead them to embark on a medical shopping tour in the endeavor to find someone who will tell them what they want to hear. They hope to be told that the problem is minor and that the child will outgrow it.

These mixed feelings toward the child and his handicap lead many parents to adopt distorted ways of behaving toward the youngster. The attitude of overprotection is most common. Somewhat less common, but equally damaging, is subtle or even overt rejection.

The pediatrician can help parents to work through and understand such distortions, enabling them to adopt a more realistic attitude toward the child. With such help, parents can insure the child's chances of a healthy personality development.

One of the most basic needs of any child is to feel that he is loved. Mature parental love means not only the giving of affection, but also requiring of the child those behaviors which are appropriate for his age. With a handicapped child the parents are apt to get off the track in either one or both of these areas. For example, they may smother the child with affection in a way that immobilizes him into an infantilism extending 
far beyond infancy. They may also require little of him in the way of social conformity.

That these attitudes stem from hostility rather than love may be sensed by the child, who then begins to feel that he is not loveable or acceptable - that he is some kind of inferior product. He feels rejected and not really an accepted part of the family as he conceives his siblings to be. Such basic resentment as is then engendered often causes him to rebel both against his family and against his handicap.

Diabetic children often react in this fashion. Peter, an eleven-year-old boy whose diabetes was first diagnosed at the age of seven, is an example. From its recovery onward he had become an increasing behavior problem both at home and in school. He was defiant and surly and resisted all authority. He began stealing money which he often used to buy candy for himself and his friends. He resisted taking his insulin and frequently ignored his diet. He was often brought in diabetic coma to the emergency room.

A more thorough investigation revealed his parent's very mixed feelings toward his diabetes. His father openly resented the extra work and money involved, and would say so in front of Peter. The mother had become increasingly overprotective toward him and he sensed that she too resented his disease. He felt rejected, was naturally angry, and was acting out this anger toward all adults. At the same time he kept trying to prove that he didn't really have diabetes, by flaunting all medical regimens. To help the parents adopt a more healthy attitude toward Peter and to help him accept the diabetes and realize it did not make him an outcast was difficult and time-consuming.

\section{Discipline for the Handicapped Child}

Here is another aspect which often needs to be discussed with parents. Consistent and reasonable discipline is a necessary ingredient of all child rearing. Youngsters experiment with many kinds of behavior in order to determine what limits will be set by their parents and what the price is for ignoring these rules. They find security in learning that the rules are both reasonable and consistent. Conversely, changing the rules or punishments from day to day keeps the child off balance and unsure of what he can and cannot do. This principle of course holds for the normal child just as much as for the handicapped one.

Spanking is a form of discipline which many parents can use comfortably with normal children, but cannot handle with a handicapped child. Spanking is usually triggered by parental irritation, and this may be too closely related to the parent's basic resentment of the child. When certain behavior leads to a spanking for the normal siblings but not for him, this reinforces his feeling of "being different" and of not really belonging. Parents often need help in understanding the wisdom of similar disciplinary measures for all of their children. In a surprising number of cases, parental expectations for the handicapped do not vary significantly from those for normal children.

\section{Peer Relationships}

Another potential problem for the handicapped child is that of peer relationships. To generalize, other children tend to view the handicapped child much as he views himself. When his handling at home has led him to feel that he is not really loveable and acceptable, he will both expect and elicit rejection from other youngsters. Children will quickly discover this sensitivity and will taunt him. When, however, the handicapped child has come to accept his difficulty and is secure in his relationships with his parents, he will expect and most probably develop normal friendships with his peers. Children can accept marked handicaps in other youngsters when such disabilities are accepted by the child himself.

The pediatrician may need to initiate discussion with parents of the handicapped child's relationships with ouner youngsters. With peer problems the parents should be helped to understand that they are rooted in the child's own feelings about himself and that wise parental handling can improve his self-image. 